STUDI

FRANCESI

\section{Studi Francesi}

Rivista quadrimestrale fondata da Franco Simone

170 (LVII | II) | 2013

Varia

\title{
Journaux intimes, de Madame de Staël à Pierre Loti, présentés et annotés par Michel Braud
}

\section{Catherine Thomas-Ripault}

\section{(2) OpenEdition}

1 Journals

\section{Édition électronique}

URL : https://journals.openedition.org/studifrancesi/3124

DOI : 10.4000/studifrancesi.3124

ISSN : 2421-5856

Éditeur

Rosenberg \& Sellier

\section{Édition imprimée}

Date de publication : 1 juillet 2013

Pagination : 465-466

ISSN : 0039-2944

\section{Référence électronique}

Catherine Thomas-Ripault, « Journaux intimes, de Madame de Staël à Pierre Loti, présentés et annotés par Michel Braud », Studi Francesi [En ligne], 170 (LVII | II) | 2013, mis en ligne le 01 juillet 2013, consulté le 02 février 2023. URL : http://journals.openedition.org/studifrancesi/3124 ; DOI : https:// doi.org/10.4000/studifrancesi.3124

Ce document a été généré automatiquement le 2 février 2023.

\section{(c) (†) $\ominus$}

Creative Commons - Attribution - Pas d'Utilisation Commerciale - Pas de Modification 4.0 International - CC BY-NC-ND 4.0

https://creativecommons.org/licenses/by-nc-nd/4.0/ 


\title{
Journaux intimes, de Madame de Staël à Pierre Loti, présentés et annotés par Michel Braud
}

\author{
Catherine Thomas-Ripault
}

\section{RÉFÉRENCE}

Journaux intimes, de Madame de Staël à Pierre Loti, textes choisis, présentés et annotés par Michel BRAUD, Paris, Gallimard, 2012, pp. 606.

1 Cette anthologie nous permet de plonger dans l'intimité d'écrivains appartenant au large XIX ${ }^{e}$ siècle, et de mieux comprendre le développement et les limites d'un genre qui se situe aux frontières de beaucoup d'autres mieux définis. La richesse du corpus - pas moins de vingt-neuf auteurs, célèbres ou inconnus, figurent dans cet ouvrage, de Rétif de la Bretonne à Léon Bloy - permet d'appréhender cette écriture dans ses multiples variations et dans ses nuances les plus infimes.

Onze journaux parmi tous ceux qui nous sont présentés furent rédigés entre 1800 et 1850: les extraits du journal de Maine de Biran (pp. 87-105) révèlent un être en proie à une grande timidité, soucieux d'analyser minutieusement ses sentiments et leur évolution; Benjamin Constant (pp. 106-121) apparaît, dans les quelques pages issues de son journal, «cette espèce de secret ignoré de tout le monde» (p. 113), en proie aux doutes et à la solitude, s'attachant à écrire l'histoire de sa vie avec la plus grande sincérité; Stendhal (pp. 122-144) analyse longuement ses réactions, ses sentiments, ses espoirs, saisis jour après jour, tandis que Maurice de Guérin livre dans son Cahier vert (pp. 145-153) réflexions et souvenirs en une prose poétique qui fait de ce texte un véritable objet littéraire. Fort différent, le journal d'Eugénie de Guérin (pp. 154-165) prend la forme d'une longue lettre adressée à son frère, auquel elle rapporte les menus événements de son quotidien. Les extraits des journaux de Marie d'Agoult (pp. 166-176) ou de George Sand (pp. 177-186) nous livrent les confidences de deux femmes 
passionnées, la première éprise de Franz Liszt, la seconde évoquant avec de déchirants accents sa rupture avec Musset. Plus apaisé, le journal de Delacroix (pp. 187-205) retrace les impressions et les moments vécus par le peintre, qui écrit pour lutter contre ses «variations» (p. 189) ou tenter de maîtriser le temps: «en conservant l'histoire de ce que j'éprouve, écrit-il, je vis double; le passé redeviendra à moi. L'avenir est toujours là» (p. 196). Le Journal d'un poète (pp. 206-222) présente une sélection de notes issues de carnets tenus par Alfred de Vigny, dans lesquels il consignait ses réflexions sur la vie, la littérature, et relatait certains événements de son quotidien, comme la mort de sa mère qui figure dans les extraits choisis. Les memoranda de Barbey d'Aurevilly (pp. 223-238) s'adressent toujours à un destinataire précis - Maurice de Guérin, Trébutien, ou celle qu'il nomme «l'Ange Blanc; ils veulent recueillir les petits événements de la vie quotidienne et saisir les impressions qu'ils suscitèrent: «Ces pages sont un kaléidoscope, car je dois déposer au fur et à mesure toutes les nuances que je revêts» (p. 229), note Barbey. Enfin les pages extraites du journal de Michelet (pp. 239-264) qui furent écrites avant 1850 concernent essentiellement des réflexions face à la disparition du père de l'écrivain ou de sa première femme, et l'observation amoureuse d'Athénaïs, sa deuxième épouse, dont l'évocation donne lieu à des passages empreints de sensualité et de poésie.

Confidences amoureuses, quête de vérité, réflexions sur la vie, le temps, la mort, étude de soi et des autres, impressions de voyage, mention des petits faits de la vie quotidienne, nous livrent au fil de ces pages l'histoire intime d'un siècle qui assiste à la naissance de l'individu. Le choix des textes, qui se succèdent selon un ordre chronologique, répond à une volonté de conserver le ton adopté dans l'ensemble du journal dont ils sont extraits, de représenter la diversité des thèmes traditionnellement abordés sous cette forme littéraire, et de privilégier les passages dans lesquels le diariste porte un regard réflexif sur sa propre pratique. Ainsi le lecteur peut-il placer le journal intime dans une perspective historique, et appréhender les différentes fonctions qui lui sont assignées au fil du temps et selon la sensibilité des écrivains.

4 La préface de Michel Braud (pp. 7-35), fort éclairante, montre comment le journal répond à une "exigence intérieure» et s'inscrit dans la volonté de mieux se connaitre. Replaçant le genre dans une perspective historique, l'auteur retrace rapidement les différents facteurs, sociologiques, philosophiques ou techniques, qui suscitèrent la naissance du journal intime, avant de saisir les liens qui le relient à d'autres formes d'écriture. Abordant la question du véritable destinataire du journal - écrit-on vraiment pour soi, ou dans le secret espoir d'être lu? -, de sa réception critique ou de sa valeur esthétique, Michel Braud soulève les principales problématiques qui s'attachent à une forme littéraire emblématique du XIX ${ }^{\mathrm{e}}$ siècle. Nous pouvons cependant regretter que la multiplicité des texte choisis, si elle permet d'élargir notre connaissance du genre et de découvrir des personnalités variées, nous interdise d'entrer suffisamment dans l'univers personnel d'un auteur: la nécessaire brièveté des extraits impose le rapide passage de l'un à l'autre, quand on souhaiterait mieux s'imprégner de chacun d'entre eux. L'objet de cette anthologie n'est pourtant pas tant de saisir la complexité d'une conscience que de partir à la découverte d'un genre et d'un siècle littéraire; il est en ce sens parfaitement atteint. 